\title{
Music Listening Activities in the Digital Age An Act of Cultural Participation through Adequate Music
}

\author{
RAPHAËL NOWAK
}

This article discusses how the digital age

of music technologies has contributed to the transformation of the activities of music listening, highlighting cultural participation in distinct worlds through "adequate music."

Listening consists of perceiving an auditory stimulus through hearing. It is performed by a subject who listens to a sonic object. The activity of listening is contextualized within a particular environment that mediates the conditions of listening. During listening activities, all individuals' senses are mobilized. This is the reason why discourses on listening must encompass the interactions between the subject, their senses and attention span over the course of the listening activity, the actual music content listened to, the technology used to do so and the environment within which the activity unfolds.

The conditions of listening activities evolve over time. The technological variable has encountered a number of recent technical and material changes. Practices of music production, distribution and consumption are said to have been transformed by the technological upheavals that have marked the digital age of recorded music. Little is however said about how this potentially transforms the actual activities of listening. Instead, scholars often analyze practices of consumption through the use of a particular digital objectfor example, the iPod-and explore their meanings.

Beyond providing revolutionary cultural changes, digital technologies contribute in increasing the presence of music throughout the various environments of everyday life. Moreover, a second element to consider is that they multiply the material presence of music. The major consequence of these aforementioned outcomes is to turn listening activities into

Raphaël Nowak (teaching associate), School of Sociology, Politics and International Studies, University of Bristol, 11 Priory Road, Bristol, BS8 1TU, U.K. Email: <raph.nowak@gmail.com>.

See <www.mitpressjournals.org/toc/lmj/-/26> for supplemental files associated with this issue sites of cultural struggle. If music is omnipresent, then its meaning is increasingly contested. It becomes an even greater marker of cultural participation to particular worlds. In navigating the various environments of everyday life, listeners seek an "adequate music" [1] in phase with their desire to be in the world.

This article is divided in two sections. The first section discusses the different variables that compose listening activities and identifies how the digital age of music technologies has induced changes in such listening activities. The second section explores how individuals attempt to grasp the adequate music to participate in specific worlds.

\section{THE DIGITAL AGE OF MUSIC LISTENING}

Listening is performed in the interaction between a subject (listener) and an object (speech, noises, music, etc.). In the case of music, listening mostly consists of interacting with recorded sounds and is therefore performed through particular technological artifacts. The action of listening unfolds within time and space, hereafter referred to as the environment of the listening activity. In that regard, listening is mediated by a number of elements that arouse individuals' senses and alter the meaning of music. I depict these elements as a system of interactions in an attempt to explain listening activities. However, approaches to the issue of listening tend to highlight one variable above others. In this section, I explore some accounts of listening and argue that the changes induced by the digital age of music technologies require an even more dynamic and interactive perspective on listening activities.

Critical theorist Theodor Adorno locates the meaning of listening activities within the actual object, or content, of listening. His influential perspective on popular music is deeply rooted in a political analysis of the culture industry from a Marxist approach. In his 1941 text "On Popular Music," he pursues a distinction between "serious music" and "popular music" on the basis of how each type of music is produced and what it communicates. He argues that listening to either produces particular affects, or stimuli, in individuals. "This contrasting character of the standardization ... provides a 
rough, preliminary setting for the effect upon the listener" [2]. Popular music is standardized, and listeners can therefore predict the whole sequence of the songs to which they listen: "The listener can supply the 'framework' automatically, since it is a mere musical automatism itself" [3]. Hence, listening to popular music is effortless. It makes listeners passive in their interactions with music. To Adorno, this is because "popular music commands its own listening habits" [4].

In the example of this influential theory, the meaning of listening activities is embedded within the content itself. This leads philosopher Nick Zangwill to argue that Adorno discusses music in quite an "arbitrary" fashion. In a severe critique, he writes: "The disappointing truth is that Adorno is just reporting on his own idiosyncratic form of musical listening, one overlaid by extraneous ideologies" [5]. Turning to the sociology of music provides a greater sense of how multiple subjectivities can define popular music through listening practices.

In the sociology of music, there is an attempt to broaden the focus on listening by drawing on the idea that music is an object that is diffused within context(s). Tia DeNora takes the task of critically assessing the input of Adorno and argues that "music analysis, traditionally conceived as an exercise that 'tells' about the 'music itself', is insufficient as a means for understanding musical affect" [6]. To DeNora, music has affordances to which listeners respond, affordances that they use as possibilities of action within their everyday lives. Her approach identifies music listening activities as diffused and contextualized. This results in a less politically charged theory intended to place the subjectivity of listeners at the core of everyday listening practices. Nonetheless, issues of technologies and materiality are missing from DeNora's sociological perspective [7].

The work of Jonathan Sterne (2006) sheds light upon the role of technological artifacts in our everyday interactions with music. In exploring the $\mathrm{MP}_{3}$ file as an auditory technology, he argues that the file "contain[s] a praxeology of listening" [8]. He continues by arguing that the dominant digital format is "designed to be heard via headphones while outdoors, in a noisy dorm room, in an office with a loud computer fan, in the background as other activities are taking place and through low-fi or mid-fi computer speakers" [9]. However, regardless of how the technology is "designed," or what it "contains," it is then embedded within a system of interactions that composes listening activities. Conclusions on what technologies "enable," "make people do" or "are designed to do" neglect the dynamic process through which they are integrated.

The digital age of music technologies has participated in increasing the presence of music in everyday life and across a variety of environments. Music is not only there; it is a possibility. With the advent of digital technologies, the materiality of music is only further emphasized [10]. Objects are compared and contrasted in terms of what listening activity they induce. Individuals multiply their listening activities through the array of technological options at their disposal, affecting how they unfold within particular everyday en- vironments [11]. Thus, within the contemporary landscape of recorded music, listening entangles various types of activities and materialities, from listening at home to a CD, vinyl disc, streaming service; on the go through individual or recommended playlists on an iPod or a smartphone; or to "ubiquitous music" [12] that is played within particular social environments (shopping malls, tube or train stations, hotel lobbies and so on).

The configurations of listening proliferate with the number of options from which to choose. Thus the question is not whether music is "ubiquitous" or listened to in a private and individualized fashion. Both configurations coexist and are difficult to measure and quantify. The scope of sociological research on listening to music must interrogate the kind of engagement individuals have with music and with what result.

If music is mediated, then the meaning of listening activities changes. It is to be investigated in context. The environment of the listening activity mediates the relationship between individuals and music through listening, and it creates a system of interactions between the subject, the music content, the technology used to do so and the environment within which the listening activity occurs. By accounting for the dynamic interactions of these variables, my sociological approach considers listening activities as uncertain in their outcomes, with individuals engaging in an endeavor to grasp upon the "adequate music."

\section{LISTENING, PARTICIPATION AND THE PURSUING OF ADEQUATE MUSIC}

Listening means participating in a cultural world. Listening activities are a mode of engagement with an environment, as mediated by the sound of music and how it affects listeners. For instance, in listening to music broadcast in a shoe store, individuals participate in the sonic environment as defined by the person in charge of choosing the music providing a suitable ambiance for the store. All individuals' senses are tuned to how the environment is composed. If an individual chooses to block out the shoe store music by listening to a personal playlist, or to an algorithmically curated playlist, the mode of engagement differs. The experience of being in the shoe store is then mediated by the different music content listened to. The mode of participation changes.

The very possibility of engagement in various listening activities is a product of a technological and cultural evolution. Sterne (2003) points out how the technocultural framework transforms how individuals listen, and the functions of listening, over time [13]. In the digital age of music technologies and the multiple material sources from which music now emanates, music listening activities become a site of struggle. In our contemporary attention economy, music participates in defining everyday environments by particular moods or ambiances, which encourage individuals to act, behave and consume in certain fashions. In turn, the omnipresence of music augments the contestation of its meaning.

To Zangwill, listening "does not have political content," but it "has political consequences" [14]. The political consequences of listening concern the type of cultural partici- 
pation within everyday environments in which individuals want to engage. In that regard, it is not the content of listening activities that is political-as Adorno argues [15] — but the very mode of engagement in listening that acts as a political statement. French philosopher Jean-Luc Nancy (2007) highlights how listening represents a way to "be in the world" [16]. In a time of ubiquitous music, listening activities can be done in opposition to other ones. Music can challenge other music. Listening to some music rather than other music becomes a statement. It means participating in $a$ world. In opposition, it also means refusing to participate in other worlds. Music delineates and demarcates these different worlds and, consequently, the type of cultural participations in them.

The motivations behind cultural participation in different worlds are to be sought within the possibility for music to affect individuals in certain fashions. In his research on listening, Antoine Hennion (2007) provides the most detailed sociological scrutiny of listening activities. Drawing on a microscale analysis of music listeners that focuses on the actual "journey" of listening, Hennion depicts the active engagement of individuals through bodily practices that are aimed at becoming more receptive to the actual sound of music. Moreover, besides this activity of "tasting" music through listening, listening occurs within an environment that Hennion sees as mediated by various elements:

To accentuate listening is to reintroduce into taste the act of tasting: the irreducible heterogeneity of a real event, not only the masterpiece and the listener, . . but of bodies, of devices and dispositions, of duration, an ungraspable object, an instant that passes, states that emerge [17].

Individuals gather as much as possible from the content listened to and therefore increase the musical pleasure resulting from the listening activity. Hennion insists on the uncertain outcome of listening activities. What emerges from his input is individuals' endeavor to seize upon the "adequate music" within particular environments.

Musicologist Ola Stockfelt (1997) argues that music can be "adequate" to particular environments. To him, a genre of music is associated with a number of codes and places. For instance, mainstream popular music may be adequate to a shoe store where individuals engage in consumerist actions, and the genre opera adequate to an opera house where individuals are appropriately dressed up for the occasion [18]. To Stockfelt, music genres are associated with a number of listening situations. This means that music can be adequately diffused within an array of environments. Adequate listening occurs when music fits in with an environment. Stockfelt's account represents a shift from Adorno's argument locating the right music in the content listened to toward a dynamic perspective wherein music content and environment are coconstructed. The right way to listen to music becomes the adequate way to listen to music.

In light of the changes induced by the digital age of music technologies on the importance of material objects in listening activities, Stockfelt's input needs to be updated. With the multiplicity of options from which individuals choose in engaging in listening activities, the question of adequate music and adequate listening relates to the type of cultural participation that they favor. Music is listened to adequately when it results in the affects that were initially sought when engaging with the music. As such, listening activities provide the affective resource that individuals pursue throughout the various environments of their everyday lives [19]. Adequate music can be defined as a symbiosis between how individuals engage in listening activities - through a choice of technology, content and with bodily postures [20] — and how these activities unfold within a particular everyday environment. Adequate listening anchors the participation of individuals within particular cultural worlds. In turn, adequate music truly highlights the potential of music to represent a resource that not only accompanies but also helps individuals perform certain tasks. Music is a resource when adequately listened to, which means that it produces the affects sought after by the subject and it is appropriately associated with the activity within which it generates such affects. For instance, when music is adequate to the activity of running, it enables individuals to participate in the environment within which they run in the way that they intend. It is the listening activity that changes the perception of the environment and that encourages individuals to participate in it the way that they intended.

Adorno argues that listening is "manipulated," notably by a "system of response mechanisms wholly antagonistic to the ideal of individuality" [21]. In fact, the possibilities for configuration of listening activities are now greater, through the range of technological options and music content. Hence, individuals contest the meaning of music by engaging with it in various ways, which all affirm a mode of cultural engagement to a particular world.

\section{CONCLUSION}

This article explores the changes induced by the digital age of music technologies on listening activities. Digital technologies contribute in making music more ubiquitous and multiply its material presence. Music is contested in its meaning and its presence. In fact, listening activities become sites of cultural struggle for the adequate music that is most suited to an environment. Listening activities become greater markers of cultural participation in specific worlds. When options multiply, choosing one over others becomes a statement about a mode of engagement with music and a type of participation to a cultural world.

With this perspective on listening, I argue that listening activities are composed of a system of interactions between four variables (subject, object, technology and environment), which are contextualized and dynamic. In an age of digital technologies and ubiquitous music, the very presence and meaning of music is contested. The ubiquity of music is challenged by what functions it is supposed to perform. Technologies are thus explored through how they are diffused within particular modes of cultural engagement through music. 


\section{References and Notes}

1 O. Stockfelt, "Adequate Modes of Listening," in D. Schwarz et al., eds., Keeping Score: Music, Disciplinarity, Culture (Charlottesville, VA: University Press of Virginia, 1997).

2 T. Adorno, “On Popular Music," Soundscapes: Journal on Media Culture 2 (2000 [1941]), available at <www.icce.rug.nl/ soundscapes /DATABASES/SWA/On_popular_music_1.shtml>.

3 Adorno [2].

4 Adorno [2].

5 N. Zangwill, "Listening to Music Together," British Journal of Aesthetics 52, No. 4, 379-389 (2012) p. 381.

6 T. DeNora, Music in Everyday Life (New York: Cambridge Univ. Press, 2000) p. 23.

7 R. Nowak, "Investigating the Interactions between Individuals and Music Technologies within Contemporary Modes of Music Consumption," special edition "Napster, 15 years on: Rethinking digital music distribution," First Monday 19, No. 10 (2014).

8 J. Sterne, "The Mp3 as Cultural Artifact," New Media Society 8, No. 5, 825-842 (2006) p. 828.

9 Sterne [8] p. 835 .

10 P. Magaudda, "When Materiality 'Bites Back': Digital Music Consumption Practices in the Age of Dematerialization," Journal of Consumer Culture 11, 15-36 (2011).
11 R. Nowak, "Investigating the Interactions between Individuals and Music Technologies within Contemporary Modes of Music Consumption," special edition "Napster, 15 years on: Rethinking digital music distribution," First Monday 19, No. 10 (2014).

12 A. Kassabian, Ubiquitous Listening. Affect, Attention and Distributed Subjectivity (Los Angeles: University of California Press, 2013).

13 J. Sterne, Audible Past. Cultural Origins of Sound Reproduction (London: Duke Univ. Press, 2003).

14 Zangwill [5] p. 382.

15 Adorno [2].

16 J-L Nancy, Listening (New York: Fordham Univ. Press, 2007).

17 A. Hennion, “Those Things That Hold Us Together: Taste and Sociology," Cultural Sociology 1, No. 1, 97-114 (2007) p. 106.

18 Stockfelt [1].

19 DeNora [6].

20 Hennion [17].

21 Adorno [2].

Manuscript received 2 January 2016.

RAPHAËL NOWAK is a cultural sociologist who currently teaches at the University of Bristol (U.K.).

\section{ANNOUNCING}

\section{Leonardo Art Science Evening Rendezvous (LASER)}

Since 2008, the Leonardo Art Science Evening Rendezvous (LASER) series of lectures and presentations on art, science and technology has provided spaces for progressive thought leaders to come together to form community and explore the intersections of disciplinary thinking. Owing to its success and popularity, LASER has expanded beyond its birthplace in the San Francisco Bay Area, first to the U.S. East Coast, then across the Atlantic to London - the home of the first European LASER - and today continues to expand to new locations nationally and internationally. We thank all of those who have spoken at, participated in or attended LASER events throughout the years. We owe a special thank you to Piero Scaruffi, LASER founder and chair, for his inspiration and continued dedication, and to the growing list of LASER hosts around the world. To follow LASER events, see <www.leonardo.info/isast/laser.html>. 